\title{
Comparative electroretinograms in argon laser and xenon arc panretinal photocoagulation
}

\author{
JAMES C. LIANG, ${ }^{1}$ GERALD A. FISHMAN, ${ }^{1}$ FELIPE U. HUAMONTE, ${ }^{1}$ AND \\ ROBERT J. ANDERSON ${ }^{2}$ \\ From the ${ }^{1}$ University of Illinois Eye and Ear Infirmary and the ${ }^{2}$ Epidemiology and Biometry Program, \\ School of Public Health, University of Illinois, Chicago, USA
}

SUMMARY We performed electroretinograms (ERG) on both eyes of 11 diabetic patients before and one month after panretinal photocoagulation for diabetic retinopathy. Each patient had one eye treated with argon laser and the fellow eye treated with the xenon arc photocoagulator. After photocoagulation the ERG was symmetrically reduced unless the retinal area burned with xenon arc was greater than twice the retinal area burned in the fellow eye by the argon laser photocoagulator.

Panretinal photocoagulation (PRP) has been shown to reduce the risk of blindness caused by moderate to advanced proliferative diabetic retinopathy. ${ }^{1}$ The amount of retinal destruction following PRP may determine the effectiveness of the treatment. We used electroretinograms (ERGs) following argon laser and xenon arc panretinal photocoagulation to evaluate the amount of functional retina destroyed.

\section{Materials and methods}

Eight men and 3 women with bilateral symmetrical severe nonproliferative diabetic retinopathy (DRS group 3$)^{1}$ or proliferative diabetic retinopathy without vitreous contraction (DRS groups 4-6) ${ }^{1}$ were selected. All were white and their ages ranged from 19 to 60 years with a mean of 43.5 years.

Each patient had a complete ophthalmic examination including best corrected visual acuity, slit-lamp examination, intraocular pressure measurement, and dilated direct and indirect ophthalmoscopy. Fundus photographs and fluorescein angiography were also obtained. Their retinopathy was classified by the modified Airlie House classification.

Each patient received panretinal photocoagulation (PRP) in one eye with an argon laser and in the fellow eye with a xenon arc photocoagulator. The types of

Correspondence to Dr J. C. Liang, to Department of Ophthalmology, University of Southern California, Estelle Doheny Eye Foundation Building, 1355 San Pablo St, Los Angeles CA 90033. USA. treatment were randomly assigned for each eye. The PRP treatments were carried out in one to 3 sessions at least 2 weeks apart. The treatment technique has been previously described. ${ }^{2}$ The treatment parameters are summarised in Table 1.

Electroretinograms were performed in both eyes before and one month after treatment of the second eye by a modification of a procedure previously described. ${ }^{3}$ Specifically, photopic $a$ and $b$ wave amplitudes and implicit times were determined as well as 20 minute scotopic a and b wave amplitudes and implicit times using a white light with the $I_{16}$ setting on a Grass PS-2 photostimulator. The normal intertesting variability in our laboratory is between 5 and $15 \%$ for the ERG amplitudes and is 2 milliseconds for the ERG implicit times.

Table 1 Panretinal photocoagulation treatment parameters

\begin{tabular}{lll}
\hline & Argon laser(11 eyes) & Xenon arc (11 eyes) \\
\hline Timing & \multicolumn{1}{c}{$0 \cdot 1 \mathrm{~s}$} & Manual \\
$\begin{array}{l}\text { Spot size } \\
\text { Intensity }\end{array}$ & $500 \mu \mathrm{m}$ & $4 \cdot 5^{\circ}$ \\
$\quad$ Range & $200-800 \mathrm{~mW}$ & GII-RII \\
$\quad$ Typical setting & $450 \mathrm{~mW}$ & GIII \\
$\begin{array}{l}\text { Burns per sessions } \\
\text { Range }\end{array}$ & $200-940$ & $72-269$ \\
$\quad$ Mean & 552 & 139 \\
Total burns & & \\
$\quad$ Range & $957-1710$ & $217-309$ \\
Mean & 1217 & 265 \\
\hline
\end{tabular}


The retinal area burned was calculated for each eye from the formula:

$$
\begin{aligned}
& \text { Area }=\mathrm{n} \pi(\mathrm{s} / 2)^{2} \\
& \text { Where } \\
& \mathrm{n}=\text { number of burns } \\
& \mathrm{s}=\text { size of burns in } \mathrm{mm} \text {. }
\end{aligned}
$$

Thus a $500 \mu \mathrm{m}$ spot is $0.20 \mathrm{~mm}^{2}$ and $4.5^{\circ}$ spot is 1.77 $\mathrm{mm} .{ }^{2}$ The retinal surface constitutes about two-thirds of the total surface area of the globe. In an eye with a $24 \mathrm{~mm}$ diameter the total retinal area is about $1200 \mathrm{~mm}^{2}$.

\section{Results}

The retinal area and percentage of the total retinal area burned was consistently greater $(p=0 \cdot 000012)$ with xenon arc PRP than with argon laser PRP (Table 2). The individual panretinal photocoagulation data are presented in Table 3.

The pre- and post-treatment ERG photopic and scotopic responses are presented in Tables 4 and 5, respectively; the ERG response changes and percentage changes are presented in Tables 6 and 7 . ERG tracings from one patient (no. 6) were not available for detailed review at the time of this report and are omitted from Tables 4-7. However, a prior descriptive reading done at the time the ERG was performed was in the chart, so this patient is included in Tables $1-3$.

The reduction in the ERG was symmetrical between the 2 eyes of most patients. When the calculated retinal area burned by xenon PRP was more than twice as great as the calculated retinal area burned by argon PRP, the ERG amplitude reduction was greater in the xenon treated eye by $15 \%$ or more for the a wave, $b$ wave, or both $a$ and $b$ waves. Of the 6 patients with xenon/argon treated area ratios greater than $2 \cdot 00$, this finding was observed in 5 patients. In the one patient (no. 10) in whom this did not hold true the ERG $a$ and $b$ wave amplitudes were the lowest of those found in all the patients. This would be con-

\begin{tabular}{|c|c|c|c|c|c|c|c|c|}
\hline \multirow[t]{2}{*}{ Patient } & \multirow{2}{*}{$\begin{array}{l}\text { Age } \\
\text { (years) }\end{array}$} & \multirow[t]{2}{*}{ Sex } & \multicolumn{2}{|c|}{ Baseline vision } & \multicolumn{2}{|l|}{ Latest vision } & \multicolumn{2}{|c|}{ Follow-up in months } \\
\hline & & & Argon & Xenon & Argon & Xenon & Argon & Xenon \\
\hline 1 & 19 & $\mathbf{M}$ & $6 / 15(20 / 50)$ & $6 / 15(20 / 50)$ & $6 / 12(20 / 40)$ & $6 / 12(20 / 40)$ & 49 & 47 \\
\hline 2 & 46 & $\mathbf{M}$ & $6 / 9(20 / 30)$ & $6 / 30(20 / 100)$ & $6 / 15(20 / 50)$ & $6 / 30(20 / 100)$ & 15 & 17 \\
\hline 3 & 58 & $\mathbf{M}$ & $6 / 15(20 / 50)$ & $6 / 60(20 / 200)$ & $6 / 21(20 / 70)$ & $6 / 30(20 / 100)$ & 13 & 9 \\
\hline 4 & 31 & $\mathbf{M}$ & $6 / 24(20 / 80)$ & $6 / 9(20 / 30)$ & $6 / 18(20 / 60)$ & $6 / 18(20 / 60)$ & 13 & 11 \\
\hline 5 & 37 & $\mathbf{M}$ & $6 / 90(20 / 300)$ & $6 / 18(20 / 60)$ & $6 / 240(20 / 800)$ & $6 / 60(20 / 200)$ & 23 & 24 \\
\hline 6 & 58 & $\mathbf{M}$ & $6 / 9(20 / 30)$ & $6 / 7 \cdot 5(20 / 25)$ & $6 / 9(20 / 30)$ & $6 / 7 \cdot 5(20 / 25)$ & 54 & 49 \\
\hline 7 & 55 & $\mathbf{F}$ & $6 / 24(20 / 80)$ & $6 / 24(20 / 80)$ & $6 / 6(20 / 20)$ & $6 / 12(20 / 40)$ & 24 & 23 \\
\hline 8 & 28 & $\mathbf{M}$ & $6 / 9(20 / 30)$ & $6 / 7 \cdot 5(20 / 25)$ & $6 / 9(20 / 30)$ & $6 / 12(20 / 40)$ & 19 & 17 \\
\hline 9 & 34 & $\mathbf{F}$ & $6 / 6(20 / 20)$ & $6 / 7 \cdot 5(20 / 25)$ & $6 / 15(20 / 50)$ & $6 / 4 \cdot 5(20 / 15)$ & 38 & 36 \\
\hline 10 & 53 & $\mathrm{~F}$ & $6 / 9(20 / 30)$ & $6 / 12(20 / 40)$ & $6 / 7 \cdot 5(20 / 25)$ & $6 / 60(20 / 200)$ & 13 & 15 \\
\hline 11 & 60 & $\mathbf{M}$ & $6 / 9(20 / 30)$ & $6 / 9(20 / 30)$ & $6 / 7 \cdot 5(20 / .5)$ & $6 / 7 \cdot 5(20 / 25)$ & 17 & 9 \\
\hline \multicolumn{3}{|c|}{$\begin{array}{r}\text { Summary } 43 \cdot 5 \\
\text { (Mean) }\end{array}$} & $\begin{array}{l}6 / 21(20 / 50) \\
\text { (Median) }\end{array}$ & $\begin{array}{l}6 / 18(20 / 45) \\
\text { (Median) }\end{array}$ & $\begin{array}{l}6 / 30(20 / 45) \\
\text { (Median) }\end{array}$ & $\begin{array}{l}6 / 24(20 / 50) \\
\text { (Median) }\end{array}$ & $\begin{array}{l}25 \cdot 3 \\
\text { (Mean) }\end{array}$ & $\begin{array}{l}23.4 \\
\text { (Mean) }\end{array}$ \\
\hline
\end{tabular}
sistent with marked retinal ischaemia. Presumably panretinal photocoagulation of these widespread

\begin{tabular}{|c|c|c|c|c|c|c|c|c|}
\hline \multirow[t]{2}{*}{ Patient } & \multicolumn{2}{|c|}{ Eye treated } & \multicolumn{2}{|c|}{ Phocoagulation, total burns } & \multicolumn{2}{|c|}{ Retinal area burned $\left(\mathrm{mm}^{2}\right)$} & \multirow{2}{*}{$\begin{array}{l}\text { Ratio of } \\
\text { xenon/argon } \\
\text { burned areas }\end{array}$} & \multirow[t]{2}{*}{ ERG effect } \\
\hline & Argon & Xenon & Argon & Xenon & Argon & Xenon & & \\
\hline 1 & $\mathbf{R}$ & $\mathrm{L}$ & 1710 & 217 & $342 \cdot 0$ & $384 \cdot 1$ & $1 \cdot 12$ & $X=A$ \\
\hline 2 & $\mathbf{L}$ & $\mathbf{R}$ & 1440 & 254 & $254 \cdot 0$ & $449 \cdot 6$ & $1 \cdot 56$ & $X=A$ \\
\hline 3 & L & $\mathbf{R}$ & 1167 & 244 & 253.4 & $431 \cdot 9$ & $1 \cdot 85$ & $X=A$ \\
\hline 4 & $\mathbf{R}$ & $\mathrm{L}$ & 1197 & 258 & $239 \cdot 4$ & $456 \cdot 7$ & 1.91 & $X=A$ \\
\hline 5 & $\mathrm{~L}$ & $\mathbf{R}$ & 1148 & 250 & $229 \cdot 6$ & $442 \cdot 5$ & 1.93 & $\mathrm{X}=\mathrm{A}$ \\
\hline (6) & L & $\mathbf{R}$ & (1032) & $(239)$ & $(206 \cdot 4)$ & $(423 \cdot 0)$ & $(2 \cdot 05)$ & $(X>A)$ \\
\hline 7 & $\mathbf{R}$ & $\mathrm{L}$ & 1218 & 282 & 243.6 & $499 \cdot 1$ & $2 \cdot 05$ & $X>A$ \\
\hline 8 & $\mathrm{~L}$ & $\mathbf{R}$ & 1228 & 291 & $246 \cdot 6$ & $515 \cdot 1$ & $2 \cdot 10$ & $X>A$ \\
\hline 9 & $\mathrm{~L}$ & $\mathbf{R}$ & 1109 & 269 & $221 \cdot 8$ & $476 \cdot 1$ & $2 \cdot 15$ & $X>A$ \\
\hline 10 & $\mathbf{R}$ & L & 1178 & 302 & $235 \cdot 6$ & $534 \cdot 5$ & $2 \cdot 27$ & $X=A$ \\
\hline 11 & L & $\mathbf{R}$ & 957 & 309 & $191 \cdot 4$ & 546.9 & $2 \cdot 86$ & $\mathbf{X}>\mathbf{A}$ \\
\hline Summary & $4 R$ & $4 \mathrm{~L}$ & 1217 & 265 & $240 \cdot 3$ & $469 \cdot 0$ & & $6 X=A$ \\
\hline & $7 \mathrm{~L}$ & $7 \mathbf{R}$ & (Mean) & (Mean) & (Mean) & (Mean) & & $5 X>A$ \\
\hline
\end{tabular}

Table 2 Baseline and follow-up clinical data

Table 3 Individual panretinal photocoagulation treatment data 
ischaemic areas might result in a more or less equal amount of functioning retina being coagulated with both the argon laser and xenon arc.

Both $\mathrm{a}$ and $\mathrm{b}$ wave amplitudes were proportionally reduced, a finding that was expected, since damage is known to occur within both cone and rod photoreceptor outer segments; both photopic (lightadapted) and scotopic (dark-adapted) findings were similarly affected.

When all 10 patients whose ERGs were available for detailed review were analysed as a group, it was found that the xenon treated eyes as a group had a significant reduction $(p=0.025)$ in the photopic a wave amplitude as compared with the argon treated eyes. The photopic $b$ wave was also reduced more in the xenon treated than the argon treated eyes, but the statistical significance $(p=0.12)$ was borderline, indicative of the variability in this small group of patients. There were significantly greater reductions in the scotopic a wave $(p=0.031)$ and $b$ wave $(p=$ $0 \cdot 026)$ in the xenon treated eyes as compared with the argon treated eyes.

Implicit times were unchanged in 9 patients, while 2 patients showed increased photopic and scotopic a and $b$ wave implicit times following xenon arc photocoagulation. There were no significant differences (photopic a wave, $p=0 \cdot 17$; $b$ wave, $p=0 \cdot 13$; scotopic a wave, $p=0 \cdot 11 ; b$ wave, $p=0 \cdot 15)$ in the implicit time between the 10 xenon treated and 10 argon treated eyes.

\section{Discussion}

The Diabetic Retinopathy Study has shown that panretinal photocoagulation with the argon laser or xenon arc can reduce the risk of severe visual loss due

Table 4 ERG photopic responses*

\begin{tabular}{|c|c|c|c|c|c|c|c|c|}
\hline \multirow[t]{3}{*}{ Patient } & \multicolumn{4}{|l|}{ Xenon } & \multicolumn{4}{|l|}{ Argon } \\
\hline & \multicolumn{2}{|c|}{ Pretreatment } & \multicolumn{2}{|c|}{ Post-treatment } & \multicolumn{2}{|c|}{ Pretreatment } & \multicolumn{2}{|c|}{ Post-treatment } \\
\hline & $\begin{array}{l}\text { a wave } \\
\mu \nu \text { (ms) }\end{array}$ & $\begin{array}{l}b \text { wave } \\
\mu v(m s)\end{array}$ & $\begin{array}{l}a \text { wave } \\
\mu v(m s)\end{array}$ & $\begin{array}{l}b \text { wave } \\
\mu v(m s)\end{array}$ & $\begin{array}{l}a \text { wave } \\
\mu v(m s)\end{array}$ & $\begin{array}{l}b \text { wave } \\
\mu v(m s)\end{array}$ & $\begin{array}{l}\text { a wave } \\
\mu \nu \text { (ms) }\end{array}$ & $\begin{array}{l}b \text { wave } \\
\mu \nu(m s)\end{array}$ \\
\hline 1 & $60(14)$ & $200(28)$ & $40(14)$ & $120(28)$ & $40(14)$ & $180(28)$ & $30(14)$ & $110(28)$ \\
\hline 2 & $20(18)$ & $100(36)$ & $10(20)$ & $50(36)$ & $20(18)$ & $100(36)$ & $10(20)$ & $50(36)$ \\
\hline 3 & $30(16)$ & $90(30)$ & $20(20)$ & $50(36)$ & $30(16)$ & $100(30)$ & $20(16)$ & $50(32)$ \\
\hline 4 & $60(16)$ & $140(36)$ & $30(16)$ & $80(36)$ & $60(16)$ & $150(36)$ & $30(16)$ & $70(36)$ \\
\hline 5 & $30(14)$ & $130(28)$ & $20(14)$ & $60(28)$ & $30(16)$ & $130(32)$ & $20(16)$ & $60(32)$ \\
\hline 6 & $\ldots$ & $\ldots$ & $\ldots$ & $\ldots$ & $\ldots$ & $\ldots$ & & $\ldots$ \\
\hline 7 & $40(14)$ & $150(32)$ & $10(14)$ & $60(32)$ & $40(14)$ & $150(30)$ & $20(14)$ & $80(30)$ \\
\hline 8 & $50(12)$ & $190(30)$ & $20(12)$ & $80(32)$ & $50(12)$ & $180(30)$ & $40(12)$ & $120(32)$ \\
\hline 9 & $50(18)$ & $150(30)$ & $30(18)$ & $90(30)$ & $50(18)$ & $150(30)$ & $40(18)$ & $140(30)$ \\
\hline 10 & $20(18)$ & $100(34)$ & $10(18)$ & $40(36)$ & $20(18)$ & $100(34)$ & $10(18)$ & $40(34)$ \\
\hline 11 & $50(16)$ & $160(32)$ & $10(20)$ & $50(40)$ & $40(16)$ & $160(34)$ & $20(16)$ & $80(34)$ \\
\hline
\end{tabular}

${ }^{*}$ In each column of ERG responses the amplitude in microvolts $(\mu \mathrm{v})$ is listed first, followed by the implicit time in milliseconds $(\mathrm{ms})$.

Table 5 ERG scotopic responses*

\begin{tabular}{|c|c|c|c|c|c|c|c|c|}
\hline \multirow[t]{3}{*}{ Patient } & \multicolumn{4}{|l|}{ Xenon } & \multicolumn{4}{|l|}{ Argon } \\
\hline & \multicolumn{2}{|c|}{ Pretreatment } & \multicolumn{2}{|c|}{ Post-treatment } & \multicolumn{2}{|c|}{ Pretreatment } & \multicolumn{2}{|c|}{ Post-treatment } \\
\hline & $\begin{array}{l}\text { a wave } \\
\mu \nu(m s)\end{array}$ & $\begin{array}{l}b \text { wave } \\
\mu v \text { (ms) }\end{array}$ & $\begin{array}{l}\text { a wave } \\
\mu v(m s)\end{array}$ & $\begin{array}{l}b \text { wave } \\
\mu v(m s)\end{array}$ & $\begin{array}{l}\text { a wave } \\
\mu v(m s)\end{array}$ & $\begin{array}{l}b \text { wave } \\
\mu v(m s)\end{array}$ & $\begin{array}{l}\text { a wave } \\
\mu v(m s)\end{array}$ & $\begin{array}{l}b \text { wave } \\
\mu v(m s)\end{array}$ \\
\hline 1 & $240(18)$ & $550(50)$ & $120(18)$ & $270(48)$ & $210(18)$ & $520(50)$ & $130(18)$ & $280(28)$ \\
\hline 2 & $160(24)$ & $390(56)$ & $60(24)$ & $160(56)$ & $140(24)$ & $370(56)$ & $50(24)$ & $140(56)$ \\
\hline 3 & $200(20)$ & $400(46)$ & $60(26)$ & $130(50)$ & $210(20)$ & $390(46)$ & $70(20)$ & $160(46)$ \\
\hline 4 & $210(24)$ & $500(52)$ & $100(24)$ & $250(52)$ & $200(22)$ & $510(52)$ & $110(22)$ & $260(52)$ \\
\hline 5 & $190(18)$ & $340(44)$ & $100(20)$ & $160(46)$ & $180(20)$ & $340(46)$ & $100(20)$ & $160(48)$ \\
\hline 6 & & $\ldots$ & & $\ldots$ & .. & & $\ldots$ & $\ldots$ \\
\hline 7 & $160(22)$ & $540(50)$ & $40(22)$ & $180(50)$ & $160(22)$ & $560(50)$ & $80(22)$ & $260(50)$ \\
\hline 8 & $200(20)$ & $600(54)$ & $60(20)$ & $200(54)$ & $200(20)$ & $620(54)$ & $70(20)$ & $300(54)$ \\
\hline 9 & $200(22)$ & $560(50)$ & $60(22)$ & $200(50)$ & $180(22)$ & $560(50)$ & $120(22)$ & $350(50)$ \\
\hline 10 & $120(26)$ & $250(52)$ & $40(26)$ & $70(54)$ & $130(24)$ & $270(52)$ & $40(24)$ & $70(52)$ \\
\hline 11 & $180(22)$ & 390 (44) & $70(26)$ & $160(58)$ & $200(24)$ & $400(44)$ & $100(24)$ & $260(46)$ \\
\hline
\end{tabular}

${ }^{*}$ In each column of ERG responses the amplitude $(\mu \mathrm{v})$ is listed first, followed by the implicit time ( $\left.\mathrm{ms}\right)$. 
to proliferative diabetic retinopathy. ${ }^{1}$ While the exact mechanisms for the beneficial effects of panretinal photocoagulation are unknown, it is thought that destruction of a highly metabolically active photoreceptor retinal pigment epithelium complex is important.

In this study the ERG and the retinal area burned are compared to evaluate the relative functional damage to retinal photoreceptors caused by 2 somewhat different types of treatment. It would appear that functional impairment of the retinal photoreceptors as assessed electrophysiologically was similar after PRP by either the argon laser or xenon arc. This was true until the calculated area of the xenon arc PRP burns exceeded 2.00 times the calculated area of the xenon laser PRP burns. Both a and $b$ waves were affected, confirming destruction of photoreceptor outer segments. Electrophysiological functional impairment was equally apparent under photopic and scotopic conditions.

Table 6 ERG photopic response changes*

\begin{tabular}{|c|c|c|c|c|c|c|c|c|c|c|c|c|c|c|c|c|}
\hline \multirow[t]{4}{*}{ Patient } & \multicolumn{8}{|c|}{ Xenon } & \multicolumn{8}{|c|}{ Argon } \\
\hline & \multicolumn{4}{|c|}{ a wave } & \multicolumn{4}{|c|}{ b wave } & \multicolumn{4}{|c|}{ a wave } & \multicolumn{4}{|c|}{$b$ wave } \\
\hline & \multicolumn{2}{|c|}{ Amplitude } & \multicolumn{2}{|c|}{ Implicit time } & \multicolumn{2}{|c|}{ Amplitude } & \multicolumn{2}{|c|}{ Implicit time } & \multicolumn{2}{|c|}{ Amplitude } & \multicolumn{2}{|c|}{ Implicit time } & \multicolumn{2}{|c|}{ Amplitude } & \multicolumn{2}{|c|}{ Implicittime } \\
\hline & $\mu v$ & $\%$ & $\mathrm{~ms}$ & $\%$ & $\mu \mathrm{v}$ & $\%$ & $\mathrm{~ms}$ & $\%$ & $\mu v$ & $\%$ & $\mathrm{~ms}$ & $\%$ & $\mu \mathrm{v}$ & $\%$ & $\mathrm{~ms}$ & $\%$ \\
\hline 1 & -20 & -33 & 0 & 0 & -80 & -40 & 0 & 0 & -10 & -25 & 0 & 0 & -70 & -39 & 0 & 0 \\
\hline 2 & -10 & -50 & +2 & +11 & -50 & -50 & () & 0 & -10 & -50 & +2 & +11 & -50 & -50 & 0 & 0 \\
\hline 3 & -10 & -33 & +4 & +25 & -40 & -44 & +6 & +20 & -10 & -33 & 0 & 0 & -50 & -50 & +2 & +7 \\
\hline 4 & -30 & -50 & 0 & 0 & -60 & -43 & 0 & 0 & -30 & -50 & 0 & 0 & -80 & -53 & 0 & 0 \\
\hline 5 & -10 & -33 & 0 & 0 & -70 & -54 & 0 & 0 & -10 & -33 & 0 & 0 & -70 & -54 & 0 & 0 \\
\hline 6 & $\ldots$ & $\ldots$ & $\ldots$ & $\ldots$ & $\ldots$ & $\ldots$ & $\ldots$ & $\ldots$ & $\ldots$ & $\ldots$ & $\ldots$ & $\ldots$ & $\ldots$ & $\ldots$ & $\ldots$ & $\ldots$ \\
\hline 7 & -30 & -75 & 0 & 0 & -90 & -60 & 0 & 0 & -80 & -50 & 0 & 0 & -70 & -47 & 0 & 0 \\
\hline 8 & -30 & -60 & 0 & 0 & -110 & -58 & +2 & +7 & -10 & -20 & 0 & 0 & -60 & -33 & +2 & +7 \\
\hline 9 & -20 & -40 & 0 & 0 & -60 & -40 & 0 & 0 & -10 & -20 & 0 & 0 & -10 & -7 & 0 & 0 \\
\hline 10 & -10 & -50 & 0 & 0 & -60 & -60 & +2 & +6 & -10 & -50 & 0 & 0 & -60 & -60 & 0 & 0 \\
\hline $\begin{array}{l}11 \\
\text { Mean }\end{array}$ & -40 & $\begin{array}{l}-80 \\
-50 \cdot 4\end{array}$ & +4 & +25 & -90 & $\begin{array}{l}-56 \\
-50 \cdot 5\end{array}$ & +8 & +25 & -20 & $\begin{array}{l}-50 \\
-38 \cdot 1\end{array}$ & 0 & 0 & -80 & $\begin{array}{l}-50 \\
-44 \cdot 3\end{array}$ & 0 & 0 \\
\hline
\end{tabular}

${ }^{*}$ Response change $(\mu \mathrm{v}$ or $\mathrm{ms})=$ post-treatment - pretreatment.

$\%$ Response change $=\frac{\text { Post }- \text { treatment }- \text { pretreatment }}{\text { pretreatment }} \times 100$.

Normal amplitude variability is $5-15 \%$ for our laboratory. Normal implicit time variability is $2 \mathrm{~ms}$ for our laboratory.

Table 7 ERG photopic response changes*

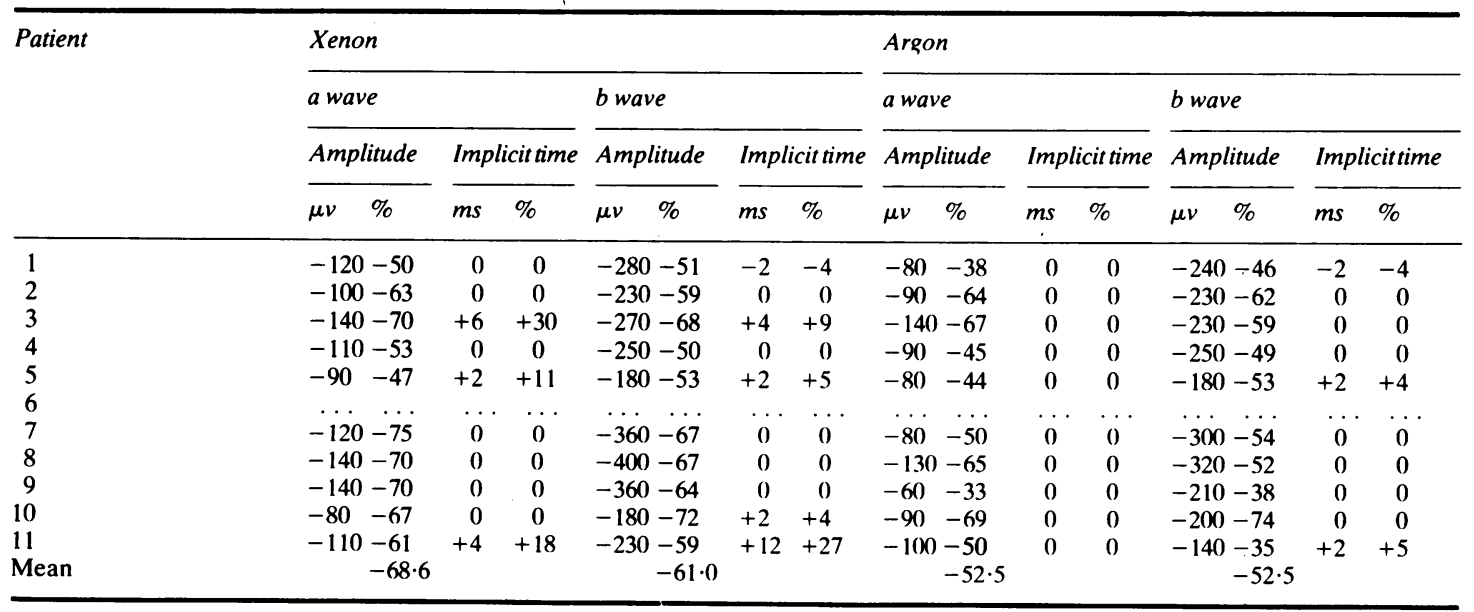

${ }^{*}$ Response change $(\mu \mathrm{v}$ or $\mathrm{ms})=$ Post-treatment - pretreatment.

$\%$ Response change $=\frac{\text { Post-treatment }- \text { pretreatment }}{\text { pretreatment }} \times 100$.

Normal amplitude variability is $5-15 \%$ for our laboratory. Normal implicit time variability is 2 ms for our laboratory. 
Frank $^{4}$ determined that ERG b wave amplitudes were reduced by an average of $40 \%$ in a group of 24 eyes receiving extensive argon laser PRP for proliferative or preproliferative diabetic retinopathy. $\mathrm{He}$ suggested that the photoreceptors in approximately $40 \%$ of the retinal area were destroyed by the PRP treatments.

Ogden and associates ${ }^{5}$ performed argon laser or xenon arc PRP on 14 eyes. They measured a decrease in ERG amplitude that varied from 10 to $95 \%$ among the patients and also an increase in ERG latency and implicit time in several patients. They suggested that there was a wide variability in the area of retina affected by the treatment, although they did not calculate the area of retina treated. They also suggested the possibility of the PRP affecting adjacent untreated retina in some diabetic patients.

Schuurmans and associates ${ }^{6}$ performed intense xenon arc PRP in 5 rabbits, treating either the nasal retina, the posterior pole, or the entire retina, after which the ERG response was compared with the histologically measured area of retinal damage. They concluded that, when less than $30 \%$ of the retina is treated, the ERG is reduced proportionally to the retinal area destroyed; when greater than $30 \%$ of the retinal surface is destroyed, the decrease in response is greater than the enlargement of the coagulated area-that is, they found that $60 \%$ retinal destruction decreased the ERG $80 \%$.

François and associates ${ }^{7}$ performed ERGs on 50 diabetic eyes before and after argon laser PRP. They found no correlation between the total number of coagulation spots and the reduction of the ERG; however, they stated that the number of coagulation spots in the perfused zones of the retina and reduction of the ERG was well correlated.

Hamilton and associates ${ }^{8}$ performed ERGs on 21 diabetic patients before, and 6 and 12 months after, panretinal photocoagulation. Each patient had one eye treated with 'gentle' $500 \mu \mathrm{m}$ argon laser burns and the fellow eye treated with 'gentle' $4.5^{\circ}$ xenon arc burns. 'It was estimated that approximately the same area was being treated and therefore the results would be comparable.' And 'In general ERG was more severely affected in the xenon than the argon group.'

Table 8 presents their data on the number of burns applied to each eye and the post-treatment ERGs. The areas burned and the ratio of the areas burned in their xenon and argon groups were calculated and included in Table 8 . The average number of xenon burns applied was 711 for an area burned of 1258 $\mathrm{mm}^{2}$. The average number of argon burns applied was 3459 for an area burned of $692 \mathrm{~mm}^{2}$. The ratio

Table 8 Panretinal photocoagulation data (from Hamilton et al. ${ }^{8}$ )

\begin{tabular}{|c|c|c|c|c|c|c|c|c|c|}
\hline \multirow[t]{2}{*}{ Patient } & \multicolumn{2}{|c|}{$\begin{array}{l}\text { Photocoagulation, } \\
\text { total burns }\end{array}$} & \multicolumn{2}{|c|}{$\begin{array}{l}\text { Retinal area, } \\
\text { burned }\left(\mathrm{mm}^{2}\right)\end{array}$} & \multirow{2}{*}{$\begin{array}{l}\text { Ratio of } \\
\text { xenon/argon } \\
\text { burned areas }\end{array}$} & \multicolumn{2}{|c|}{$\begin{array}{l}E R G \text { at } 6 \\
\text { months }\end{array}$} & \multicolumn{2}{|c|}{$\begin{array}{l}\text { ERG at } 12 \\
\text { months }\end{array}$} \\
\hline & Argon & Xenon & Argon & Xenon & & Argon & Xenon & Argon & Xenon \\
\hline 1 & 7474 & 896 & 1495 & 1586 & $1 \cdot 06$ & $\mathbf{N}$ & $\mathbf{S}$ & $\mathbf{S}$ & $\mathrm{S}$ \\
\hline 2 & 5114 & 753 & 1023 & 1333 & $1 \cdot 30$ & $\mathbf{N}$ & $\mathrm{S}$ & $\mathbf{N}$ & $\mathbf{S}$ \\
\hline 3 & 3546 & 979 & 709 & 1733 & $2 \cdot 44$ & \multicolumn{2}{|c|}{ (skin ERG) } & \multicolumn{2}{|c|}{ (skin ERG) } \\
\hline 4 & 2170 & 676 & 434 & 1197 & $2 \cdot 76$ & $\mathrm{~S}$ & $\mathrm{~S}$ & NS & $\mathrm{S}$ \\
\hline 5 & 3878 & 612 & 776 & 1083 & $1 \cdot 40$ & S & $\mathbf{S}$ & $\mathrm{N}$ & $\mathbf{S}$ \\
\hline 6 & 2020 & 459 & 404 & 812 & $2 \cdot 01$ & $\mathbf{N}$ & $\mathrm{S}$ & $\mathrm{S}$ & $\mathrm{S}$ \\
\hline 7 & 4249 & 659 & 850 & 1166 & $1 \cdot 37$ & $\mathrm{~S}$ & $\mathrm{~S}$ & $\mathrm{~S}$ & $\mathrm{~S}$ \\
\hline 8 & 5708 & 1208 & 1142 & 2138 & $1 \cdot 87$ & $\mathrm{~S}$ & $\mathrm{~S}$ & $\mathbf{N}$ & $\mathbf{N}$ \\
\hline 9 & 2700 & 393 & 540 & 696 & $1 \cdot 29$ & $\mathrm{~S}$ & $\mathrm{~S}$ & $\mathrm{~S}$ & $\mathbf{S}$ \\
\hline 10 & 4960 & 799 & 992 & 1414 & $1 \cdot 43$ & $\mathbf{N}$ & $\mathrm{S}$ & $\mathbf{N}$ & $\mathbf{S}$ \\
\hline 11 & 2048 & 540 & 410 & 956 & $2 \cdot 33$ & $\mathbf{N}$ & $\mathrm{S}$ & $\mathbf{S}$ & $\mathbf{S}$ \\
\hline 12 & 4062 & 672 & 812 & 1189 & $1 \cdot 46$ & $\mathrm{~S}$ & $\mathrm{~S}$ & $\mathrm{~S}$ & $\mathbf{S}$ \\
\hline 13 & 3836 & 622 & 767 & 1101 & $1 \cdot 44$ & $\mathrm{~S}$ & $\mathrm{~S}$ & $\mathrm{~S}$ & S \\
\hline 14 & 2194 & 912 & 439 & 1614 & $3 \cdot 68$ & $\mathrm{~S}$ & $\mathrm{~S}$ & $\mathrm{~S}$ & $\mathrm{~N}-\mathrm{S}$ \\
\hline 15 & 2948 & 778 & 590 & 1377 & $2 \cdot 33$ & $\mathrm{~S}$ & $\mathrm{~S}$ & $\mathbf{N}$ & N-S \\
\hline 16 & 3189 & 603 & 638 & 1067 & $1 \cdot 67$ & $\mathrm{~S}$ & $\mathrm{~S}$ & $\mathrm{~S}$ & S \\
\hline 17 & 2004 & 608 & 401 & 1076 & $2 \cdot 68$ & \multicolumn{2}{|c|}{$\begin{array}{l}A \quad<\quad X \\
(\text { skin } E R G)\end{array}$} & \multicolumn{2}{|c|}{ (skin ERG) } \\
\hline 18 & 3068 & 1032 & 614 & 1827 & $2 \cdot 98$ & $\begin{array}{l}\mathrm{A}= \\
\text { (skin ER }\end{array}$ & $\mathrm{X}$ & $\begin{array}{l}\mathrm{A}= \\
\text { (skin EI }\end{array}$ & $X$ \\
\hline 19 & 1738 & 244 & 348 & 432 & $1 \cdot 24$ & $\mathbf{N}$ & $\mathrm{S}$ & $\mathrm{N}$ & S \\
\hline 20 & 2650 & 999 & 530 & 1768 & $3 \cdot 34$ & $\mathrm{~S}$ & $\mathrm{~S}$ & $\mathrm{~S}$ & $\mathrm{~S}$ \\
\hline 21 & 2551 & 519 & 510 & 919 & $1 \cdot 80$ & $\mathbf{N}$ & $\mathbf{N}$ & $\mathbf{N}$ & $\mathbf{N}$ \\
\hline Summary & $\begin{array}{l}3459 \\
\text { (Mean) }\end{array}$ & $\begin{array}{l}711 \\
\text { (Mean) }\end{array}$ & $\begin{array}{l}692 \\
\text { (Mean) }\end{array}$ & $\begin{array}{l}1258 \\
\text { (Mean) }\end{array}$ & & & & & \\
\hline
\end{tabular}

$\mathrm{N}=$ Normal. $\mathrm{S}=$ Subnormal. $\mathrm{N}-\mathrm{S}=$ Normal-subnormal. 
(xenon/argon) of these average areas burned is 1.82. The average of the ratios is 1.99 . At both 6 and 12 months 7 patients (although a different 7 at the 2 times) had a greater reduction of the ERG in the xenon treated eye than in the argon treated eye. The average of area burned ratios for these 7 patients is 1.68 as compared with $2 \cdot 15$ for the other 14 patients at 6 months. At 12 months the respective average ratios are 1.84 and 2.07 . These comparative ratios appear to be the reverse of what we found. However, Hamilton and associates published only brief qualitative summaries of their ERGs. Without their quantitative ERG data it is difficult to reanalyse their results any further. Further, their photocoagulation utilised many 'gentle' burns while our technique employed fewer moderate intensity burns.

Our results indicate that the ERG is of some use in measuring the effect of PRP treatment. However, the effect on the ERG by the area of retina coagulated can be correlated only in a moderate sense. This lack of a close correlation is a reflection of the variability of the health of different areas of the diabetic retina and also of the treatment technique. However, it is useful to know the comparative effect on the ERG for 2 types of treatment as they are commonly performed today.

The typical xenon PRP burns roughly twice the area of the typical argon PRP. This is a reasonable explanation for the greater peripheral field loss in xenon treated eyes as compared with argon treated eyes. ${ }^{18}$ It might be possible to reduce the side effects of xenon PRP while maintaining its beneficial effects by reducing the area of retina burned to correspond to a typical argon PRP.
This investigation was supported in part by research contracts EY3-2125 and EY7-2137 and Core grant EY1792 from the National Eye Institute, National Institutes of Health, Bethesda, Md; research grants from the Fight for Sight, New York City; the National Society to Prevent Blindness, New York City; and the National Retinitis Pigmentosa Foundation, Baltimore, Md. This manuscript was edited by Ann Dawson. Secretarial assistance was provided by Julie Rice and Patricia Sullivan.

\section{References}

1 Diabetic Retinopathy Study Research Group. Photocoagulation treatment of proliferative diabetic retinopathy: the second report of diabetic retinopathy study findings. Ophthalmology 1978; 85: 82-106.

2 Huamonte FU, Peyman GA, Goldberg MF, Locketz A. Immediate fundus complications after retinal scatter photocoagulation. I. Clinical picture and pathogenesis. Ophthalmic Surg 1976; 7: 88-99.

3 Fishman GA, Buckman G, Van Every T. Fundus flavimaculatus: a clinical classification. In: Lawwill $\mathrm{T}$, ed. ERG, VER and psychophysics. Doc Ophthalmol Proceedings Series. The Hague: Junk, 1977; 13: 213-20.

4 Frank RN. Visual fields and electroretinography following extensive photocoagulation. Arch Ophthalmol 1975; 93: 591-8.

5 Ogden TE, Callahan F, Riekhof FT. The electroretinogram after peripheral retinal ablation in diabetic retinopathy. $A m J$ Ophthalmol 1976; 81: 397-402.

6 Schuurmans RP, De Lege WA, Van Lith GHM, Oosterhuis JA. The influence of photocoagulation of the retina on the electroretinogram. Doc Ophthalmol 1977; 42: 369-73.

7 François J, De Rouck A, Cambie E, Castanheira-Dinis A. Electrophysiological studies before and after argon-laser photocoagulation in diabetic retinopathy. Ophthalmologica 1978; 176: 133-44.

8 Hamilton AM, Townsend C, Khoury D, Gould E, Blach RK. Xenon arc and argon laser photocoagulation in the treatment of diabetic disc neovascularisation. Part 1 . Effect on disc vessels, visual fields, and visual acuity. Trans Ophthalmol Soc UK 1981; 101: 87-92. 